OPEN ACCESS

Edited by:

Tingting Zhang,

Dalian University of Technology, China

Reviewed by:

Yun Gao,

Southeast University, China

Xianjie Hao

China University of Mining and

Technology, China

*Correspondence:

Jiqiang Zhang

2390912295@qq.com

Specialty section:

This article was submitted to

Structural Materials,

a section of the journal

Frontiers in Materials

Received: 30 August 2021 Accepted: 18 October 2021

Published: 03 November 2021

Citation:

Feng F, Li L, Zhang J, Yang Z and ChiX (2021) Strength Prediction of CoalBased Solid Waste Filler Based on BP Neural Network.

Front. Mater. 8:767031.

doi: 10.3389/fmats.2021.767031

\section{Strength Prediction of Coal-Based Solid Waste Filler Based on BP Neural Network}

\author{
Feisheng Feng ${ }^{1}$, Lirong $\mathrm{Li}^{2}$, Jiqiang Zhang ${ }^{1 *}$, Zhen Yang ${ }^{3}$ and Xiaolou Chi ${ }^{1}$ \\ ${ }^{1}$ State Key Laboratory of Mining Response and Disaster Prevention and Control in Deep Coal Mine, Anhui University of Science \\ and Technology, Huainan, China, ${ }^{2}$ Shanxi Coking Coal Group Co., Ltd., Taiyuan, China, ${ }^{3}$ College of Information Science and \\ Engineering, Henan University of Technology, Zhengzhou, China
}

The compressive strength of filling body is an important index to characterize the filling and mining effect of coal mine. In order to accurately predict the strength of coal-based solid waste filler (CBSWF) to guide the safe, efficient, and green mining of coal mine, coal gangue is used as coarse material; fly ash, desulfurization gypsum, gasification slag, and furnace bottom slag are used as fine materials; and cement is used as gelling agent. The compressive strength and bleeding rate of CBSWF are tested through orthogonal test, and the strength of CBSWF at different curing ages is predicted by using a 4-11-3 threelayer BP neural network structure. The results show that the correlation coefficient $r$ of strength prediction of CBSWF is 0.99987 , which can accurately predict the strength of CBSWF. Orthogonal test combined with the BP neural network can reduce the number of tests without losing generality, make full use of the advantages of adaptive nonlinear optimization of the BP neural network, and improve the operation efficiency of the model, fast prediction speed, and high accuracy.

Keywords: BP neural network, coal based solid waste, filling mining, strength prediction, orthogonal test

\section{INTRODUCTION}

In recent years, China's coal output has remained high, reaching 3.9 billion tons of raw coal in 2020. With the large-scale coal production capacity, there are also ecological problems such as surface subsidence, coal-based solid waste discharge, water system, and environmental pollution. In view of these problems, more and more mines adopt filling coal mining technology to effectively solve the coal-based solid waste generated in the process of coal deep processing. It has achieved good social and economic benefits (Wu et al., 2016; Wu et al., 2018; Zhang et al., 2020a).

Coal-based solid waste refers to the solid waste generated in the process of coal development and utilization, such as coal gangue, fly ash, desulfurization gypsum, and coal chemical waste residue. The multi-source coal-based solid waste forms a filling body by setting the ratio to avoid the deformation and damage of the rock mass around the stope. Therefore, exploring the strength characteristics, composition, and mechanical properties of coal-based solid waste filling is a necessary research content to ensure the filling effect. Exploring the performance of coal-based solid waste filling is mainly characterized by its compressive strength (Hao et al., 2021a). Uniaxial compressive strength (UCS) is an important parameter for rock mass classification and rock engineering design (Hao et al., 2020; Hao et al., 2021b). At present, empirical analogy method, empirical formula method, physical simulation method, elastic mechanics analysis method, and other methods are mainly used to predict the strength of filling body, but there are some problems such as lack of scientificity and low accuracy 
of prediction results (Chang et al., 2009). With the rapid development of big data and artificial intelligence, intelligent algorithm has been introduced into the field of coal mine filling mining to predict the strength of filling body. Deng et al. (2021) predict the strength of aeolian sand filling body from the aspects of data fitting degree, network error analysis, and prediction results, and constructs a prediction model based on the BP neural network model and PCA-BP neural network model. Zhang et al. (2020b) used artificial intelligence algorithm to study the proportion development of mining cementitious materials from the perspective of "black box", and obtains the optimal proportion of cementitious materials through orthogonal test and an artificial neural network model. Zhang and Deng (2020) extracted the strength prediction model of deep connected deep belief network (DBN) with input parameters, and used quantum particle swarm optimization algorithm to determine the number of hidden layer nodes and learning rate of DBN. The prediction performance of the BP neural network, RVM (relevance vector machine), and SVM (support vector machine) was compared and analyzed. Bai et al. (2020) improved the initial weight and threshold of the BP neural network through genetic algorithm, established the compressive strength prediction model of recycled thermal insulation concrete, and compared and analyzed the performance of the GA-BP neural network and BP neural network prediction model. Moon and Munira (2021) used 3days concrete strength as the prior information in neural network training, developed a neural network model based on prior information (pi-nnm) to obtain the 28-days concrete strength prediction model, and verified the prediction ability of the prediction model through practical production application. Huang et al. (2021) used the orthogonal test method to analyze the sensitivity of compressive strength and splitting strength of hybrid fiber reinforced recycled aggregate concrete (HYFRAC), proposed a hyfrac compressive strength prediction model based on the convolution neural network $(\mathrm{CNN})$, and compared and analyzed the prediction effects of the back propagation (BP) neural network model and multiple linear regression model. Zhang et al. (2021) support vector machine and a modified cuckoo algorithm are utilized to predict the compressive strength of geopolymer concrete. An orthogonal factor is introduced to modify the traditional cuckoo algorithm to update new species and accelerate computation convergence. Then, the modified cuckoo algorithm is employed to optimize the parameters in the support vector machine model. Then, the compressive strength predictive model of coal gangue-based geopolymer concrete is established with oxide content of raw materials as the input and compressive strength as the output of the model.

In the development history of the artificial neural network, the MLP (multi-layer perceptron) network has played a great role in the development of the artificial neural network. It is also considered as a real artificial neural network model. Its emergence has set off an upsurge of people's research on artificial neural network. As the initial neural network, the single-layer perceptual network (M-P model) has the following advantages: clear model, simple structure, and small amount of calculation. However, with the deepening of research work, it is found that it still has some shortcomings. For example, it cannot deal with nonlinear problems. Even if the action function of the calculation unit does not use the valve function and uses other more complex nonlinear functions, it can only solve the linear separable problem and cannot realize some basic functions, which limits its application. The only way to enhance the classification and identification ability of the network and solve the nonlinear problem is to use a multi-layer feedforward network, that is, add an implicit layer between the input layer and the output layer. A multilayer feedforward perceptron network is formed. In the mid-1980s, David Rumelhart, Geoffrey Hinton, Ronald Williams, and David Parker independently discovered the error BP training algorithm, which systematically solved the learning problem of hidden layer connection weight of the multilayer neural network and gave a complete derivation mathematically. The multilayer feedforward network using this algorithm for error correction is called BP network.

The basic BP algorithm includes two processes: signal forward propagation and error BP. That is, the error output is calculated in the direction from input to output, while the weight and threshold are adjusted in the direction from output to input. During forward propagation, the input signal acts on the output node through the hidden layer and generates the output signal through nonlinear transformation. If the actual output is inconsistent with the expected output, it will turn into the BP process of error. Error BP is to back transmit the output error layer by layer to the input layer through the hidden layer, allocate the error to all units of each layer, and take the error signal obtained from each layer as the basis for adjusting the weight of each unit. By adjusting the connection strength between the input node and the hidden layer node, and the connection strength and threshold between the hidden layer node and the output node, the error decreases along the gradient direction. After repeated learning and training, the network parameters (weight and threshold) corresponding to the minimum error are determined, and the training stops (Wang et al., 2021). At this time, the trained neural network can process the input information of similar samples and output the non-linear converted information with the minimum error.

Compared with traditional methods, the BP neural network has become the most widely used neural algorithm with its good nonlinear mapping ability, self-learning, and self-adaptive ability, and has actively explored and studied strength prediction $(\mathrm{Hu}$ et al., 2021; Ji et al., 2021; Qing et al., 2021). Wei et al. (2020) studied the influence of fly ash content on the strength of cemented backfill based on orthogonal test, and analyzed and predicted the influence law by using the BP neural network model. In Jiang et al. (2021), aiming at the influence of heterogeneity on rock strength under different strain rates, 42 quasi-static and 42 dynamic Brazilian disk experimental tests were trained, verified, and tested by the artificial neural network, and the relationship between rock strength and heterogeneity parameters under different strain rates was obtained. Through sensitivity analysis, it is found that strain rate is the most important physical quantity affecting the strength of heterogeneous rock. 


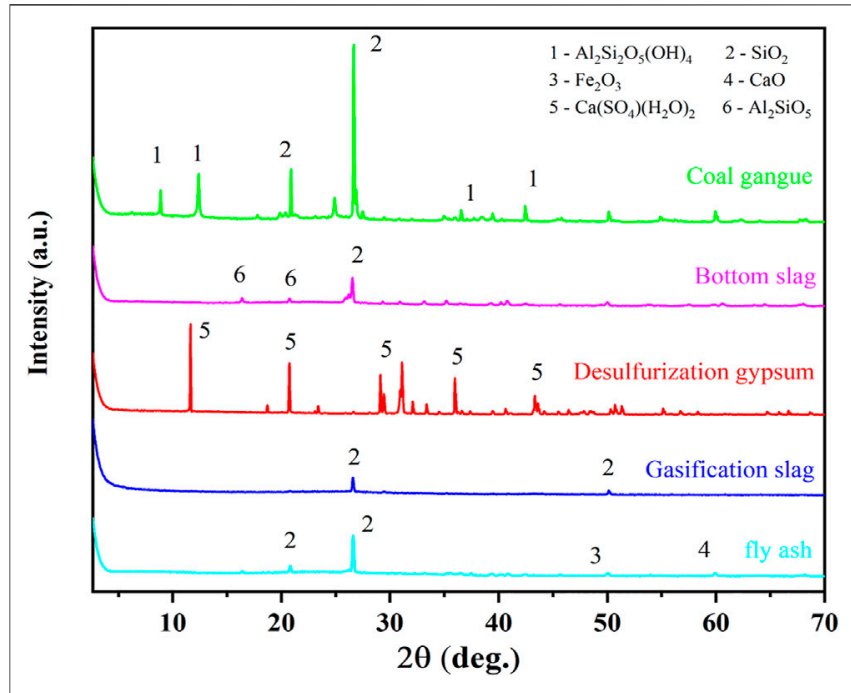

FIGURE 1 | X-ray diffraction (XRD) of coal based solid waste filling material.

Based on the BP neural network, taking coal gangue as coarse material; fly ash, desulfurization gypsum, gasification slag, and furnace bottom slag as fine material; and cement as gelling agent, the compressive strength and bleeding rate of coal-based solid waste filler (CBSWF) are tested through orthogonal test. The three-layer BP neural network of 4-11-3 is used to predict the strength of CBSWF, and the strength prediction model of CBSWF is established, The prediction results are evaluated.

\section{TEST MATERIALS AND METHODS}

\section{Material Composition}

The chemical composition of the dried CBSWF material is determined by x-ray diffraction (XRD) and x-ray fluorescence spectrum analysis (XRF). As shown in Figure 1, the main component of coal gangue is $\mathrm{SiO}_{2}$, accompanied by some silica compounds. A large amount of $\mathrm{SiO}_{2}$ ensures the high hardness and deformation resistance of gangue. Fly ash is the dry discharged ash of the Yuanyanghu power plant. The main components are $\mathrm{SiO}_{2}$, $\mathrm{Fe}_{2} \mathrm{O}_{3}$, and $\mathrm{CaO}$. The content of $\mathrm{CaO}$ and $\mathrm{SiO}_{2}$ reaches $92.27 \%$, which reduces the polymerization degree of glass in fly ash and increases its activity. The gasification slag is mainly composed of $\mathrm{SiO}_{2}$, the bottom slag is mainly composed of $\mathrm{SiO}_{2}, \mathrm{Al}_{2} \mathrm{O} 3 \bullet \mathrm{SiO}_{2}$, and $\mathrm{Fe}_{2} \mathrm{O}_{3}$, and the desulfurization gypsum is mainly composed of $\mathrm{CaSO}_{4}$ and $\mathrm{CaSO}_{4} \bullet 2 \mathrm{H}_{2} \mathrm{O}$.

\section{Test Scheme}

Using L16 $\left(4^{4}\right)$ orthogonal test, without special explanation, the ratio involved in the text is the quality ratio. Selecting the quality of coal gangue and cement as invariants, the cement content shall not exceed $5 \%$ of the total mass of coal-based solid waste. Set four research factors, namely, A (concentration), B (ash-gangue ratio), C (gasification slag: furnace bottom slag), and D (gasification slag:desulfurization gypsum), and set four horizontal gradients, as shown in Table $\mathbf{1 .}$

\section{Source and Preparation of Test Materials}

Ningdong energy and chemical base are located in the Middle East of Ningxia. In 2018, the coal output was about 91.55 million tons, the coal chemical production capacity was 22.25 million tons, and the thermal power capacity was 14.95 million $\mathrm{kW}$. In recent years, it has produced more than 90 million tons of coalbased solid wastes such as coal gangue, fly ash, desulfurization gypsum, gasification slag, and furnace bottom slag (Yang et al., 2021). Coal gangue was used as coarse material; fly ash, gasification slag, furnace bottom slag, and desulfurization gypsum were used as fine material; and 42.5 ordinary Portland cement was used as cementitious material. Among them, coal gangue comes from Renjiazhuang and Meihuajing coal mines, and fly ash, desulfurization gypsum, gasification slag, and bottom slag come from the Yuanyanghu power plant. The geographical location of the mining area is shown in Figure 2.

The large gangue is crushed by a small jaw crusher and screened into coal gangue with a particle size of $0-5 \mathrm{~mm}$ through a standard screen. The cemented block in the material is crushed and ground and screened with a 0 - to 5mm standard screen for standby. According to GB\t50080-2016 national standard (Ministry of Housing and Urban and Rural Construction, 2016), all kinds of coal-based solid waste materials are weighed successively according to the quality fraction requirements of the design scheme. The required water is poured into the evenly mixed filling materials, and a small amount of cement is mixed. After $30 \mathrm{~s}$ of mixing, the mixed cementation material is cast into the standard cube mold of $70.7 \times$ $70.7 \times 70.7 \mathrm{~mm}$, and the surface of the mold is smooth with a scraper. Then, add some mixed cementitious materials into the plexiglass container with a height of about $120 \mathrm{~mm}$ to ensure that the height of the measured filling surface is consistent, and then seal it tightly with fresh-keeping film. After standing indoors for $24 \mathrm{~h}$, measure the separated water surface and cement slurry expansion surface. After the flat mold is placed indoors and cured for $12 \mathrm{~h}$, the sample is taken out of the mold after the test block is initially self-supporting and placed in a curing box with constant temperature and humidity of $20^{\circ} \mathrm{C}$ and humidity of $90 \% \pm 5 \%$ until taken out for testing. According to the national standard (General Institute of Coal Science Research, 2010) of $\mathrm{GB} \backslash \mathrm{t} 23561.12-2010$, complete the strength test on the electrohydraulic servo universal press (loading rate is $0.05 \mathrm{kn} / \mathrm{s}$ ), as shown in Figure 3.

\section{Test Results}

The bleeding rate and uniaxial compressive strength $(3,7$, and 28 days) of CBSWF are tested by $\mathrm{L} 16\left(4^{4}\right)$ orthogonal experiment, as shown in Table 2.

The results of bleeding rate and uniaxial compressive strength (3, 7, and 28 days) of CBSWF are shown in Figure 4. The $\mathrm{A}_{\mathrm{i}} \mathrm{B}_{\mathrm{i}} \mathrm{C}_{\mathrm{i}} \mathrm{D}_{\mathrm{i}}$ is used to characterize the optimal test scheme combination of strength, in which $\mathrm{A}, \mathrm{B}, \mathrm{C}$, and $\mathrm{D}$ represent four factors, and i (taking 1,2,3,4) represents different horizontal gradients of the corresponding factors. It can be seen that among the 16 groups of specimens, when the curing age is 3 days, the compressive strength of S15 is the largest and the compressive strength of S5 is the smallest. At this time, given A (concentration 
TABLE 1 | L16 $\left(4^{4}\right)$ orthogonal experimental factors and levels.

\begin{tabular}{|c|c|c|c|c|}
\hline \multirow[t]{2}{*}{ Level } & \multicolumn{4}{|c|}{ Factor } \\
\hline & A (Concentration/\%) & B (Ash-to-gangue ratio) & $\begin{array}{c}\text { C (Gasification slag:Bottom } \\
\text { slag) }\end{array}$ & $\begin{array}{c}\text { D (Gasification slag:Desulfurization } \\
\text { gypsum) }\end{array}$ \\
\hline L1 & 74 & 0.3 & 0.2 & 0.1 \\
\hline L2 & 76 & 0.4 & 0.25 & 0.15 \\
\hline L3 & 78 & 0.5 & 0.3 & 0.2 \\
\hline L4 & 80 & 0.6 & 0.35 & 0.25 \\
\hline
\end{tabular}

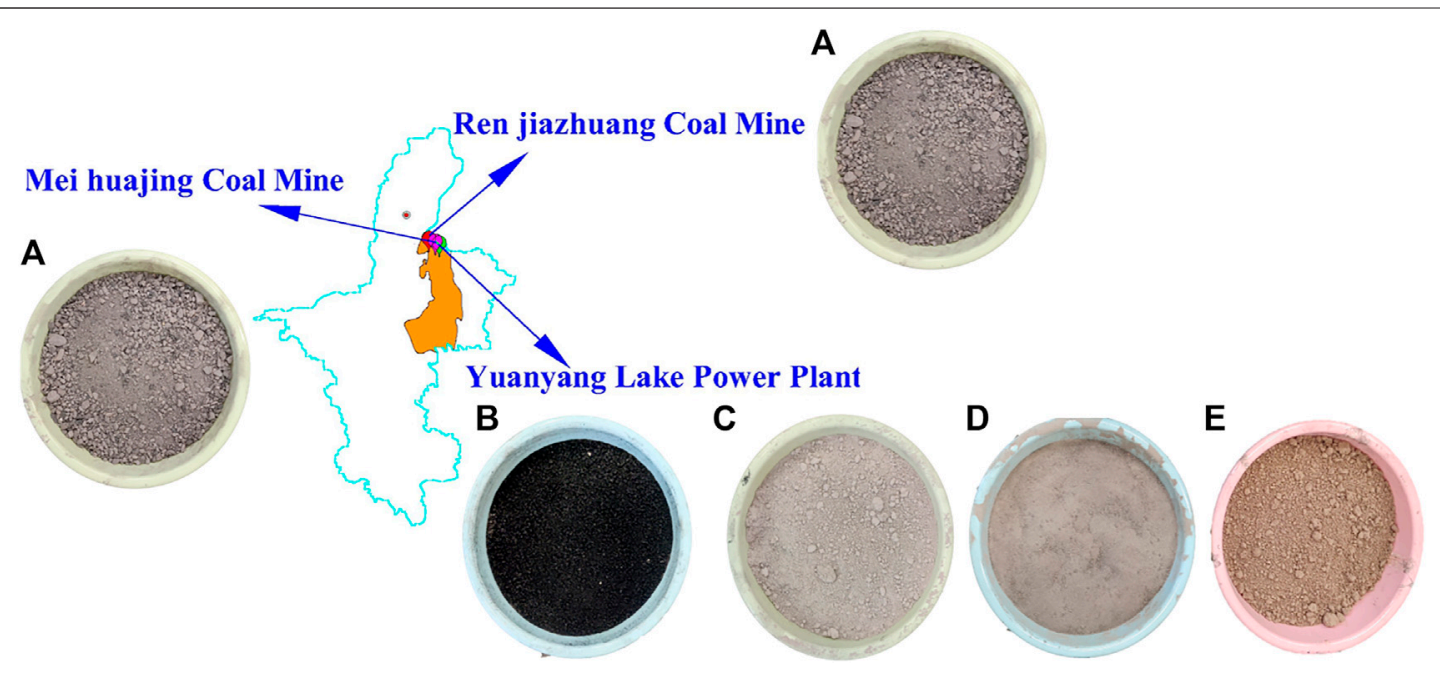

FIGURE 2 | Coal based solid waste materials: (A) coal gangue, (B) fly ash, (C) gasification slag, (D) furnace bottom slag, and (E) desulfurization gypsum.

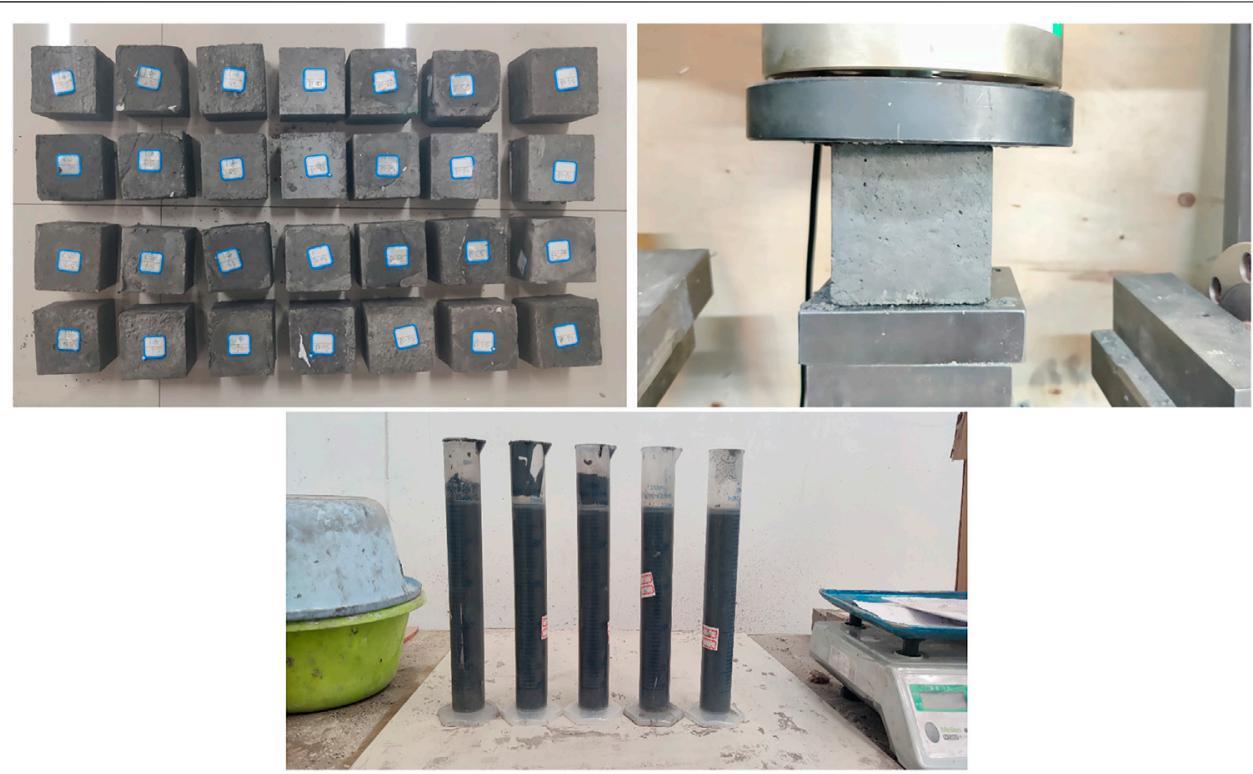

FIGURE 3 | Test pieces and test process of some CBSWF. 
TABLE 2 | Orthogonal experimental results of L16 $\left(4^{4}\right)$ CBSWF.

\begin{tabular}{|c|c|c|c|c|c|c|c|c|}
\hline \multirow[t]{2}{*}{ Group number } & \multicolumn{4}{|c|}{ Factor } & \multicolumn{3}{|c|}{ UCS/MPa } & \multirow[t]{2}{*}{ Bleeding rate $/ \%$} \\
\hline & $\mathbf{A}$ & B & C & D & 3 days & 7 days & 28 days & \\
\hline S1 & 1 & 1 & 1 & 1 & 0.184 & 0.272 & 0.254 & 1.98 \\
\hline S2 & 1 & 2 & 2 & 2 & 0.161 & 0.27 & 0.31 & 2.39 \\
\hline S3o & 1 & 3 & 3 & 3 & 0.188 & 0.361 & 0.35 & 2.42 \\
\hline S4 & 1 & 4 & 4 & 4 & 0.175 & 0.245 & 0.261 & 4.76 \\
\hline S5 & 2 & 1 & 2 & 3 & 0.147 & 0.369 & 0.448 & 2.78 \\
\hline S6 & 2 & 2 & 1 & 4 & 0.173 & 0.396 & 0.604 & 3.16 \\
\hline S7 & 2 & 3 & 4 & 1 & 0.193 & 0.345 & 0.411 & 1.22 \\
\hline S8 & 2 & 4 & 3 & 2 & 0.343 & 0.621 & 0.796 & 1.15 \\
\hline S9 & 3 & 1 & 3 & 4 & 0.368 & 0.764 & 0.626 & 1.23 \\
\hline S10 & 3 & 2 & 1 & 3 & 0.324 & 0.583 & 0.704 & 2.01 \\
\hline S11 & 3 & 3 & 4 & 2 & 0.276 & 0.571 & 0.433 & 1.49 \\
\hline S12 & 3 & 4 & 2 & 1 & 0.365 & 0.971 & 1.723 & 0.5 \\
\hline S13 & 4 & 1 & 4 & 2 & 0.348 & 0.601 & 0.616 & 4.89 \\
\hline S14 & 4 & 2 & 3 & 1 & 0.317 & 0.643 & 0.697 & 0.55 \\
\hline S15 & 4 & 3 & 2 & 4 & 0.454 & 0.809 & 0.839 & 1.08 \\
\hline S16 & 4 & 4 & 1 & 3 & 0.406 & 0.582 & 0.574 & 0.53 \\
\hline
\end{tabular}

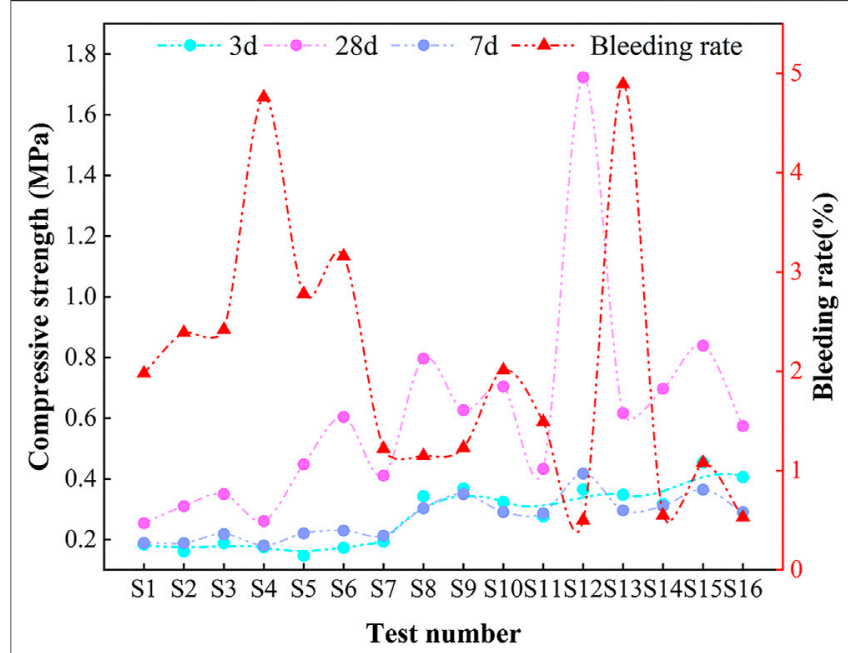

FIGURE 4 | Bleeding rate and UCS of CBSWF in different test groups.

is $80 \%$ ), $\mathrm{B}$ (ash-gangue ratio is 0.5 ), $\mathrm{C}$ (gasification slag:bottom slag is 1.67), and D (gasification slag:desulfurization gypsum is 0.7 ), the combination with the largest strength in the previous period is $\mathrm{A}_{4} \mathrm{~B}_{3} \mathrm{C}_{2} \mathrm{D}_{4}$. When the curing age is 7 and 28 days, the compressive strength and bleeding rate of $\mathrm{S} 12$ are the largest. At this time, given $\mathrm{A}$ (concentration is $78 \%$ ), $\mathrm{B}$ (ash-gangue ratio is 0.6 ), C (gasification slag:bottom slag is 1.67), and D (gasification slag:desulfurization gypsum is 1), the combination with the largest strength in the later stage is $\mathrm{A}_{3} \mathrm{~B}_{4} \mathrm{C}_{2} \mathrm{D}_{1}$.

\section{Establishment of Filling Strength Prediction Model}

The BP neural network is a multilayer feedforward neural network trained according to the error BP algorithm. It is the most widely used neural network at present. Its basic idea is the gradient descent method, which uses gradient search technology to minimize the error mean square deviation between the actual output value and the expected output value of the network. The artificial neural network does not need to determine the mathematical equation of the mapping relationship between input and output in advance. It only learns some rules through its own training and obtains the result closest to the expected output value when the input value is given.

From the orthogonal test results, it can be seen that $\mathrm{A}$ (concentration), B (ash-gangue ratio), C (gasification slag: furnace bottom slag), and D (gasification slag:desulfurization gypsum) all have an impact on the strength of CBSWF, and each factor has a nonlinear relationship with the compressive strength. It is impossible to consider all factors in the test. The neural network model can be constructed based on the existing test data to predict the unknown data. By establishing the filling strength prediction model based on the BP neural network, the disadvantages of experimental test and field monitoring being costly and time-consuming can be overcome, and a new method for filling strength prediction is provided.

Taking the bleeding rate and uniaxial compressive strength (3, 7 , and 28 days) of coal-based solid waste material filling in L16 $\left(4^{4}\right)$ orthogonal experiment as samples, the strength prediction model of CBSWF is constructed. The main structure of the model is composed of an input layer, a hidden layer, and an output layer, with A (concentration), B (ash-gangue ratio), C (gasification slag: furnace bottom slag), and D (gasification slag:desulfurization gypsum) as the network input factor in the input layer, and the 3-, 7-, and 28-days compressive strength and bleeding rate of CBSWF are taken as the network output factors. Groups S4, S8, $\mathrm{S} 12$, and S16 in the table are taken as the test set samples, and the other 12 groups of data are taken as the training set samples. The number of neurons in the hidden layer can determine the convergence of the training function, the length of training, and the size of training error, which is very important for the effect of model fitting. Many scholars have conducted a lot of research on the selection of the number of neurons in the hidden 
TABLE 3 | Average relative error of number and intensity prediction of neurons in different hidden layers.

\begin{tabular}{lccc} 
Number of hidden & \multicolumn{3}{c}{ Average relative error/\% } \\
\cline { 2 - 4 } layer neurons & 3-days UCS & 7-days UCS & 28-days UCS \\
\hline 2 & 7.207781 & 16.93408 & 37.81255 \\
3 & 5.026197 & 14.04447 & 29.14075 \\
4 & 4.596087 & 11.57161 & 29.00382 \\
5 & 6.75147 & 12.54053 & 26.81211 \\
6 & 4.668387 & 13.38517 & 27.68315 \\
7 & 3.87042 & 11.80098 & 24.66333 \\
8 & 7.376976 & 9.197673 & 23.89781 \\
9 & 8.618736 & 9.572023 & 15.31264 \\
10 & 5.594761 & 7.986225 & 23.74555 \\
11 & 3.955781 & 8.210314 & 19.59745 \\
12 & 2.952257 & 8.844902 & 23.51462 \\
\end{tabular}

layer (Adil et al., 2020; Chin and Zhang, 2021; Karmakar and Goswami, 2021). Dong et al. (2018) believe that the number of neurons in the hidden layer is optimal when $\mathrm{m}$ is $(2 \mathrm{a}+1)$, which can also be selected according to Eq. 1:

$$
\left\{\begin{array}{l}
m=\sqrt{(a+b)}+k \\
m=\log _{2} a \\
m=\sqrt{a b}
\end{array}\right.
$$

In the equation, $a$ and $b$ are the number of input factors and output factors, respectively, and $k$ is a constant between 0 and 10. The number of neurons in the hidden layer determined according to the above formula is $2-12$. The average relative error of compressive strength is used as the basis for screening the number of neurons in the hidden layer. The number of neurons in the hidden layer is determined through comparative analysis, and the network performance when the number of neurons in the hidden layer is $2-12$ is checked respectively, The prediction results and relative errors of compressive strength at different curing ages (3, 7 , and 28 days) are obtained. The relative errors obtained from each neuron are averaged, as shown in Table 3 . It is found that the relative error increases with the increase of curing age, and the worse the prediction effect. When the number of neurons in the hidden layer is 12 , the average relative error of 3-days compressive strength is the smallest, which is $2.952257 \%$. When the number is 10 , the average relative error of 7-days compressive strength is the smallest, which is $7.99 \%$. When the number is 9 , the average relative error of 28-days compressive strength is the smallest, which is $15.31 \%$. The average relative error of different curing ages is taken as the average value. It is found that when the number of neurons in the hidden layer is 11 , the relative average error is the smallest, which is $10.59 \%$. At this time, the training error will be closer to the target error. Therefore, the number of neurons in the hidden layer is 11 to predict the strength of the filling body.

At the same time, set the transfer function of input layer and output layer as purelin function, the transfer function of hidden layer as logarithmic S-type transfer function logsig, and the traingdx function is selected as the training function. The three-layer BP neural network, i.e., 4-11-3, is used to construct the strength prediction model of CBSWF, as shown in Figure 5.

In order to avoid the situation that the training time is too long to converge, before formal modeling, the data shall be preprocessed by data normalization method, the input or output data shall be transformed into dimensionless values of interval $[0,1]$ or $[-1,1]$, and the accuracy of prediction results shall be judged by means of average relative error analysis. Eq. 2 is used for normalization:

$$
x_{k}^{\prime}=\left(x_{k}-x_{\text {min }}\right) /\left(x_{\text {max }}-x_{\text {min }}\right)
$$

Where $x^{\prime}{ }_{k}$ is normalized data, $x_{k}$ is the original data, and $x_{\max }$ and $x_{\min }$ are the maximum and minimum of each group of factors, respectively. When outputting the prediction results, the data also need to be inverse normalized.

\section{DISCUSSION}

Literature (Dong et al., 2018) based on 18 groups of orthogonal test samples with mixing level, taking the content of cement clinker, desulfurization ash, Glauber's salt, and steel slag as four input factors and the 7-and 28-days compressive strength of the filling body as the output factor, $4 \times 9 \times 2$, the maximum relative errors of predicted strength at 7 and 28 days are 4.33 and $0.84 \%$. Liang et al. (2017) collected 47 groups samples. With the help of MATLAB R2015a platform and based on the BP neural network, the three-layer neural network model with single hidden layer is taken as the input with the amount of water, cement, sand, gravel, and recycled coarse aggregate per unit volume and the 28-days prism compressive strength of recycled concrete as the output. Its structure is 5-21-1. The simulation results show that the maximum relative error of prediction is $18.69 \%$. The prediction error is less than $5 \%$, accounting for $78.72 \%$ of the total sample. These studies show that using the BP neural network model to predict material strength is feasible and accurate.

Based on the above research basis, in MATLAB software, the 4-11-3 three-layer BP neural network is used to predict the strength of CBSWF. The number of training iterations is set to 1,000 steps, and the error target is set to 0.0001 . The strength

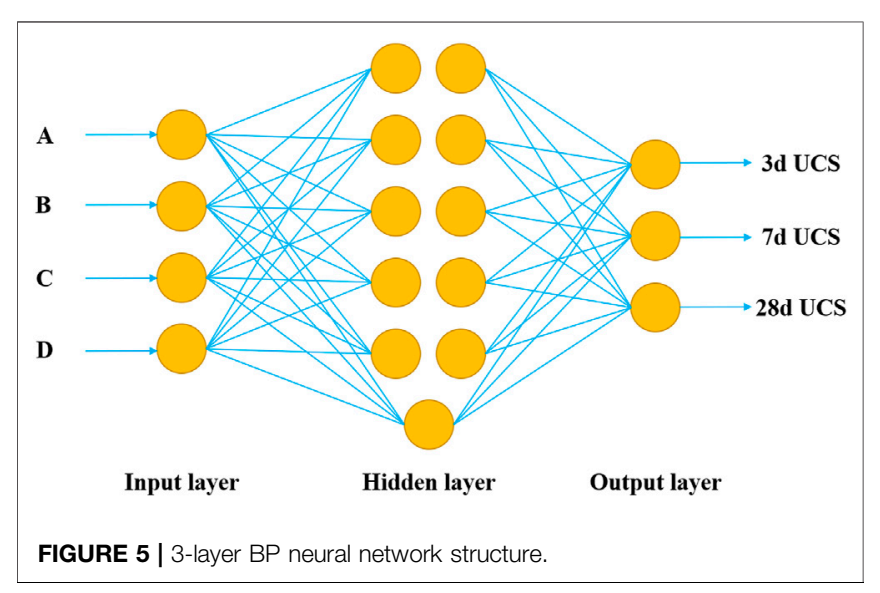


TABLE 4 | Predicted values and relative error results of strength at different curing ages.

\begin{tabular}{|c|c|c|c|c|c|c|c|c|}
\hline \multicolumn{3}{|c|}{ Training sample/MPa } & \multicolumn{3}{|c|}{ Predicted value/MPa } & \multicolumn{3}{|c|}{ Relative error/\% } \\
\hline 3 days & 7 days & 28 days & 3 days & 7 days & 28 days & 3 days & 7 days & 28 days \\
\hline 0.184 & 0.272 & 0.254 & 0.184071657 & 0.271676 & 0.266955 & 0.038944 & 0.1192 & 5.10047 \\
\hline 0.161 & 0.27 & 0.31 & 0.160392243 & 0.271525 & 0.304933 & 0.377489 & 0.564856 & 1.634526 \\
\hline 0.188 & 0.361 & 0.35 & 0.188221329 & 0.360484 & 0.350406 & 0.117728 & 0.143045 & 0.115964 \\
\hline 0.175 & 0.245 & 0.261 & 0.174891347 & 0.251718 & 0.261637 & 0.062087 & 2.742047 & 0.243983 \\
\hline 0.147 & 0.369 & 0.448 & 0.149428932 & 0.368958 & 0.448361 & 1.652335 & 0.011319 & 0.080494 \\
\hline 0.173 & 0.396 & 0.604 & 0.173030869 & 0.396149 & 0.604181 & 0.017843 & 0.037714 & 0.030044 \\
\hline 0.193 & 0.345 & 0.411 & 0.193019851 & 0.345267 & 0.411082 & 0.010285 & 0.07745 & 0.019952 \\
\hline 0.343 & 0.621 & 0.796 & 0.343120889 & 0.621032 & 0.796219 & 0.035245 & 0.005078 & 0.027552 \\
\hline 0.368 & 0.764 & 0.626 & 0.365257374 & 0.764429 & 0.626038 & 0.745279 & 0.056097 & 0.006131 \\
\hline 0.324 & 0.583 & 0.704 & 0.324107366 & 0.583084 & 0.704275 & 0.033138 & 0.014345 & 0.039103 \\
\hline 0.276 & 0.571 & 0.433 & 0.276281022 & 0.571502 & 0.433244 & 0.10182 & 0.087912 & 0.056465 \\
\hline 0.365 & 0.971 & 1.723 & 0.36465307 & 0.968911 & 1.715123 & 0.095049 & 0.215088 & 0.457157 \\
\hline 0.348 & 0.601 & 0.616 & 0.363147038 & 0.385663 & 0.286349 & 4.352597 & 35.82976 & 53.51477 \\
\hline 0.317 & 0.643 & 0.697 & 0.362841108 & 0.674051 & 0.39525 & 14.46092 & 4.829079 & 43.29265 \\
\hline 0.454 & 0.809 & 0.839 & 0.337911612 & 0.592709 & 0.564493 & 25.57013 & 26.73558 & 32.71838 \\
\hline 0.406 & 0.582 & 0.574 & 0.34257626 & 0.930597 & 1.585512 & 15.62161 & 59.89647 & 176.2215 \\
\hline
\end{tabular}
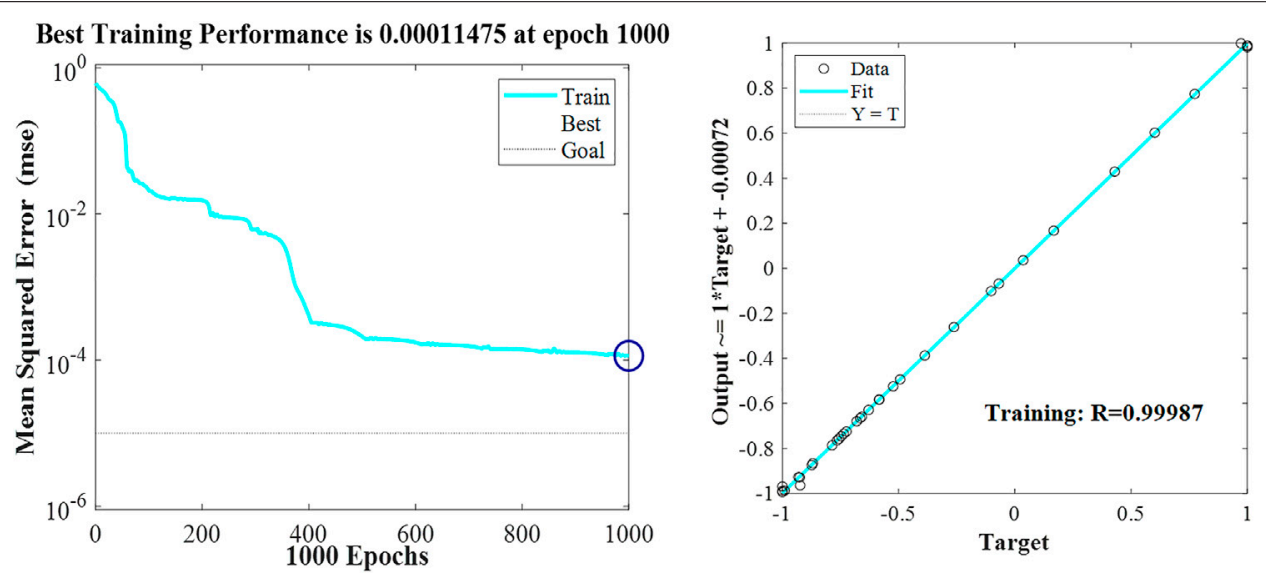

FIGURE 6 | Error convergence curve and fitting results.

prediction value and relative error results are shown in Table 4. Obviously, it can be found that the strength prediction value of S1-S12 training data in the input layer by the BP neural network is close to the test value. The maximum relative error is $5.1 \%$ of the 28 -days strength and the minimum is $0.0051 \%$ of the 7 -days strength. However, the strength prediction value of S13-S16 test data in the output layer is quite different from the test value. The relative error of the 28-days strength in S16 reaches $176.22 \%$, and the minimum value is $4.35 \%$ of the 3 -days strength in S13. The average error of the 3 -days strength is $3.95 \%$, that of the 7 -days strength is $8.21 \%$, and that of the 28 -days strength is $19.59 \%$.

The BP neural network training error convergence curve and fitting characterization of the filling strength are shown in Figure 6. The best training error is $0.0115 \%$ after 1,000 times of training in the whole training process. The effect of the whole filling strength prediction can be evaluated by fitting characterization. The solid line represents the simulation fitting curve, and the dotted line represents that the predicted value is equal to the experimental value. The $R$ value is the correlation coefficient between the predicted output and the target output. The closer the $R$ value is to 1 , it shows that the greater the correlation between the predicted output and the target output, the higher the fitting degree of the prediction model, and the better the prediction effect. It can be concluded that the correlation coefficient $r$ of the strength prediction of coal-based solid waste filling body is 0.99987 , indicating that the BP neural network is used to predict the compressive strength of filling body with high accuracy.

\section{CONCLUSION}

The following conclusions could be drawn from the current study: 
1) The compressive strength and bleeding rate of CBSWF are tested through orthogonal test. It is found that the combination with the largest early strength is $\mathrm{A}_{4} \mathrm{~B}_{3} \mathrm{C}_{2} \mathrm{D}_{4}$. When the curing age is 7 and 28 days, the compressive strength and bleeding rate of $\mathrm{S} 12$ are the largest; that is, the combination with the largest later strength is $\mathrm{A}_{3} \mathrm{~B}_{4} \mathrm{C}_{2} \mathrm{D}_{1}$.

2) The 4-11-3 three-layer BP neural network is used to predict the compressive strength of coal-based solid waste filling at different curing ages $(3,7$, and 28 days). It is concluded that the correlation coefficient $r$ of strength prediction of coalbased solid waste filling is 0.99987, and the prediction accuracy is high.

3) Orthogonal test combined with the BP neural network can reduce the number of tests without losing generality, make full use of the advantages of adaptive nonlinear optimization of the BP neural network, and improve the operation efficiency of the model, fast prediction speed, and high accuracy.

\section{DATA AVAILABILITY STATEMENT}

The original contributions presented in the study are included in the article/Supplementary Material, further inquiries can be directed to the corresponding author.

\section{REFERENCES}

Adil, M., Ullah, R., Noor, S., and Gohar, N. (2020). Effect of Number of Neurons and Layers in an Artificial Neural Network for Generalized concrete Mix Design. Neural Comput. Applic., 1-9. doi:10.1007/s00521-020-05305-8

Bai, H., Liu, Y., Guo, Y., and Zhao, M. (2020). Prediction of the Strength of Recycled Insulation concrete Based on GA-BP Neural Network. Concrete 11, $16-19+25$.

Chang, Q., Zhou, H., Qing, J., Fan, J., and Wang, Y. (2009). Using Artificial Neural Network Model to Determine the Prescription of Paste Filling Materials. J. Mining Saf. Eng. 26 (01), 74-77.

Chin, C. S., and Zhang, R. (2021). Noise Modeling of Offshore Platform Using Progressive Normalized Distance from Worst-Case Error for Optimal Neuron Numbers in Deep Belief Network. Soft Comput. 25 (1), 495-515. doi:10.1007/ S00500-020-05163-5

Deng, N., Ding, Y., Xing, C., Cao, X., and Shang, H. (2021). Wind-accumulated Sand Filler Strength Prediction Based on PCA-BP Neural Network. Mining Res. Develop. 41 (02), 109-113. doi:10.13827/j.cnki.kyyk.2021.02.019

Dong, Y., Yang, Z., and Gao, Q. (2018). Orthogonal Test in Collaboration with BP Neural Network Model to Predict Filler Strength. Mater. Guide 32 (06), 1032-1036.

General Institute of Coal Science Research (2010). The Method of Determining the Physical and Mechanic Properties of Coal and Rock Part 12: The Method of Determining the Robustness Coefficient of Coal, 8. Beijing: China's National Standardization Management Committee.

Hao, X., Du, W., Zhao, Y., Sun, Z., Zhang, Q., Wang, S., et al. (2020). Dynamic Tensile Behaviour and Crack Propagation of Coal under Coupled StaticDynamic Loading. Int. J. Mining Sci. Techn. 30 (5), 659-668. doi:10.1016/ j.ijmst.2020.06.007

Hao, X., Zhang, Q., Sun, Z., Wang, S., Yang, K., Ren, B., et al. (2021a). Effects of the Major Principal Stress Direction Respect to the Long axis of a Tunnel on the Tunnel Stability: Physical Model Tests and Numerical Simulation. Tunnell. Undergr. Space Techn. 114 (114), 103993. doi:10.1016/ J.TUST.2021.103993

\section{AUTHOR CONTRIBUTIONS}

FF contributed to the conception of the study. LL helped perform the analysis with constructive discussions. JZ performed the data analyses and wrote the article. ZY and XC helped perform the analysis with constructive discussions. All authors agree to be accountable for the content of the work.

\section{FUNDING}

We acknowledge the financial support for this work provided by the Youth Science Foundation Project (52104115), Open Foundation of State Key Laboratory of Mining Response and Disaster Prevention and Control in Deep Coal Mine (SKLMRDPC19KF10), National Key Research and Development Program (2019YFC1904304), Major special projects of science and technology in Shanxi Province (No: 20191101016).

\section{SUPPLEMENTARY MATERIAL}

The Supplementary Material for this article can be found online at: https://www.frontiersin.org/articles/10.3389/fmats.2021.767031/ full\#supplementary-material

Hao, X., Wei, Y., Yang, K., Su, J., Sun, Y., Zhu, G., et al. (2021b). Anisotropy of Crack Initiation Strength and Damage Strength of Coal Reservoirs. Pet. Explor. Develop. 48 (1), 243-255. doi:10.1016/s1876-3804(21)60020-4

Hu, S., Wang, T., Guan, Y., and Yang, Z. (2021). Regional Crustal Horizontal Motion Model of Euler-GABP Neural Network Construction. Mapp. Sci. 46 (02), 25-33. doi:10.16251/j.cnki.1009-2307.2021.02.005

Huang, W., Quan, W., and Ge, P. (2021). Orthogonal Tests Investigation into Hybrid Fiber-Reinforce Recycled Aggregate Concrete and Convolutional Neural Network Prediction. J. Asian Architect. Build. Eng., 1-16. doi:10.1080/13467581.2021.1918553

Ji, K., Han, B., Hu, Y., Wu, F., and Qiu, J. (2021). Based on the Underground Filler Strength Prediction of Strength Reduction and Intelligent Algorithm. China Nonferrous Met. J. 31 (03), 796-805.

Jiang, S., Sharafisafa, M., and Shen, L. (2021). Using Artificial Neural Networks to Predict Influences of Heterogeneity on Rock Strength at Different Strain Rates. Materials 14 (11), 3042. doi:10.3390/MA14113042

Karmakar, S., and Goswami, S. (2021). A New Procedure for Optimization of Hidden Layer Neurons during Learning through Gradient Descent Process of Neural Network and Improvement of Performance in the Chaos Forecasting. Iran J. Comput. Sci., 1-11. doi:10.1007/S42044-021-00089-Z

Liang, J., Yan, L., Hu, P., and Yang, Y. (2017). Application of BP Neural Network in Forecast to Recycled concrete Strength. Concrete (06), 9-12+16.

Ministry of Housing and Urban and Rural Construction (2016). Standard for the Performance Test Method of Ordinary concrete Mixes. Beijing: China Construction Industry Press.

Moon, S., and Munira Chowdhury, A. (2021). Utilization of Prior Information in Neural Network Training for Improving 28-Day Concrete Strength Prediction. J. Constr. Eng. Manage. 147 (5), 04021028. doi:10.1061/(ASCE)CO.19437862.0002047

Qing, N., Ge, Q., Liang, Z., Sun, J., and Wang, Y. (2021). Study on the Prediction of the Strength of the Single axis of the High Temperature on sandstone Macroscopic Damage and BP Neural Network. Exp. Mech. 36 (01), 105-113.

Wang, Y., Zhang, Y., and Chen, Y. (2021). Prediction of Concrete Slump Model Based on BP Neural Network. Int. Core J. Eng. 10 (7), 252-259. doi:10.6919/ ICJE.202110_7(10).0038 
Wei, H., Ba, L., and Gao, Q. (2020). Study on the Effect of Fly Ash Doping on the Strength of the Glycolic Filling Body. Mining Res. Develop. 40 (12), 28-32. doi:10.13827/j.cnki.kyyk.2020.12.006

Wu, A., Wang, Y., Zhou, B., and Shen, J. (2016). Effect of Initial Backfill Temperature on the Deformation Behavior of Early Age Cemented Paste Backfill that Contains Sodium Silicate. Adv. Mater. Sci. Eng. 2016, 1-10. doi:10.1155/2016/8481090

Wu, A., Yang, Y., Cheng, H., Cheng, S., and Han, Y. (2018). Status and Prospects of Paste Technology in China. Chin. J. Eng. 40 (05), 517-525. doi:10.13374/ j.issn2095-9389.2018.05.001

Yang, K., Wei, Z., Zhao, X., He, X., Zhang, J., and Ji, J. (2021). Theory and Technology of green Filling Mining of Solid Waste Underground in Coal Power Base of Yellow River Basin. J. China Coal Soc., 1-14. doi:10.13225/ j.cnki.jccs.T21.0284

Zhang, A., and Deng, F. (2020). Phosphate gypsum Filling Material Strength Prediction Based on Deep Belief Network. Sci. Techn. Eng. 20 (18), 7220-7225.

Zhang, J., Ju, F., Li, M., Zhou, N., and Zhang, Q. (2020a). Method of Coal Gangue Separation and Coordinated In-Situ Backfill Mining. J. China Coal Soc. 45 (01), 131-140. doi:10.13225/j.cnki.jccs.YG19.1826

Zhang, G., Cheng, Y., Hu, Y., and Gao, Q. (2020b). Based on the Comparison of New Filling Gel Materials of Artificial Intelligence Neural Network. Mining Res. Develop. 40 (09), 143-148. doi:10.13827/ j.cnki.kyyk.2020.09.027
Zhang, D., Sun, F., and Liu, T. (2021). Prediction of Compressive Strength of Geopolymer Concrete Based on Support Vector Machine and Modified Cuckoo Algorithm. Adv. Mater. Sci. Eng. 2021, 1-14. doi:10.1155/2021/4286810

Conflict of Interest: Author LL was employed by the company Shanxi Coking Coal Group Co., Ltd.

The remaining authors declare that the research was conducted in the absence of any commercial or financial relationships that could be construed as a potential conflict of interest.

Publisher's Note: All claims expressed in this article are solely those of the authors and do not necessarily represent those of their affiliated organizations, or those of the publisher, the editors and the reviewers. Any product that may be evaluated in this article, or claim that may be made by its manufacturer, is not guaranteed or endorsed by the publisher.

Copyright (C) 2021 Feng, Li, Zhang, Yang and Chi. This is an open-access article distributed under the terms of the Creative Commons Attribution License (CC BY). The use, distribution or reproduction in other forums is permitted, provided the original author(s) and the copyright owner(s) are credited and that the original publication in this journal is cited, in accordance with accepted academic practice. No use, distribution or reproduction is permitted which does not comply with these terms. 